\title{
Online Instructional Design Approaches Utilizing a Tablet PC
}

\author{
doi:10.3991/ijac.v2i4.993 \\ P. Lowry \\ Lawrence Technological University, Northville, Michigan, USA
}

\begin{abstract}
Online students can experience what instructional strategies can be utilized using a Tablet $P C$ in online courses. This paper summarizes how inking in Word, Powerpoint, and Windows Journal can be effective in an online course both asynchronously and synchronously. Approaches concerning assignments, discussion boards, presentations, note taking are discussed and how they can be more effective for faculty members and students using a Tablet PC. Students actually experience how a Tablet PC can be utilized in an asynchronous and synchronous environment. In summary, preliminary data will be discussed from the students and professor's point of view and next steps.
\end{abstract}

As content and assignments are being designed and developed for an online graduate course, it is important to keep in mind teaching styles, student's learning styles, and a faculty member's approach to promoting a Tablet $\mathrm{PC}$ in an online course. Even though graduate students were not required to have a Tablet $\mathrm{PC}$, the course enabled them to understand how effective a Tablet PC could be in an online course whether it was delivered asynchronous or synchronously.

Index Terms-inking, instructional strategies, online courses, Tablet PC.

\section{INTRODUCTION}

Technologies such as the Tablet PC can enhance the teaching and learning process with respect to faculty members and students. It may not meet everyone's needs but it can change the way students and faculty members interact, can add value to interaction in different learning modalities, and can support active learning.

When designing instruction pertaining to the Tablet PC, it is important to think about content, learning activities, and the desired learning outcomes. It requires deliberate instructional design that hinges on linking learning objectives to specific learning activities and measureable outcomes (Oblinger \& Lawkins, 2006). Interactivity and group work is a very effective approach when designing instruction. In designing and developing a course it is important to make the content material relevant (Harvey \& Mogey, 1997). This can pertain to many different disciplines such as education, mathematics, physics, business, humanities, and engineering.

As an online course with interactive assignments is being designed and developed, it is important to keep in mind teaching styles and student's learning styles since not all students learn the same. The findings from research on learning styles and how students receive and process information should be included when faculty members design courses.

\section{LEARNING STYLES}

As faculty members design online courses, it is important to keep in mind students' learning styles such as auditory, visual, and tactile learners. The majority of learners appear to be visual learners, followed by auditory learners, then tactile/kinesthetic learners (Waterhouse, 2005). Students will gain more knowledge, retain more information, and perform better when teaching styles match learning styles (Lage, Platt, \& Treglia, 2000).

Faculty members need to transform their teaching styles and student learning styles through some of the features of the Tablet PC. They should strive to provide a variety of learning experiences such that each learning style is addressed. The use of a variety of styles of activity and interaction can help maintain interest and can allow a course to cater to different learning styles especially in an online course (Butler, 2003).

A number of the assignments described later, utilize a combination of teaching strategies including auditory, visual and tactile strategies.

\section{A. Auditory Learners}

An auditory learner is an independent learner. Some important activities for these learners include completing some independent work. Some teaching strategies include lecturing, discussion, verbal questioning and verbal sharing. Because auditory learners like lectures, creating auditory or video recordings of lecture information and posting it can be effective (Waterhouse, 2005).

\section{B. Visual Learners}

Visual learners tend to be dependent learners that are generally group oriented. Teaching strategies that appeal to visual learners include group learning, demonstrations, and activities that emphasize creativity. Visual aids such as images, diagrams, drawings, charts, and pictures can help them form a visual image.

\section{Tactile/kinesthetic learners}

Tactile learners tend to learn by doing. They need to be actively engaged in something like open-ended questions. Teaching strategies that appeal to these learners include experiential learning activities and simulations. Tactile/kinesthetic learners have a tendency to be very creative and they like to have learning resources readily at hand (Waterhouse, 2005). 


\section{TECHNOLOGIES}

It is important for faculty members to embrace technology in teaching and some faculty members found that technology has helped them better connect with their students (Carlson, 2004). The concern is not whether technology is used; rather, how does a faculty member ensure quality and achieve learning goals when teaching via a different medium (Hutchins, 2003).

Incorporating new technologies, recognizing differences in learners, and making revisions to curriculum can enhance the learning process. The Tablet PC could make significant changes in a faculty member-student relationships involved in an asynchronous and synchronous environment.

An asynchronous learning environment is one in which students and faculty members are engaged in "anytimeanyplace" learning. Students do not have to be in the same room with other students or their instructor, nor do they all have to be engaged in a learning activity at the same time (Waterhouse, 2005). Asynchronous delivery can be accomplished through a course management system such as Blackboard, Moodle, Sakai, or others.

A synchronous learning environment is one in which students and faculty members engage each other at the same time, but not necessarily at the same location. Traditional classroom-based learning is a common form of synchronous learning (Waterhouse, 2005). Synchronous delivery can be accomplished through software such as Wimba, Centra, Skype or others.

\section{TABLET PC}

A Tablet PC can be a technology that enables faculty members to better connect with their students. How is a Tablet PC different than a standard notebook computer? It combines a standard notebook computer with a digitizing screen and a pen-like stylus device to produce a computer that allows ease of input of natural writing and drawing (Tront, Eligeti \& Prey, 2006).

Tablet PCs were implemented Fall 2007 for freshman students and faculty members teaching freshman students at Lawrence Technological University (LTU) located in Southfield, Michigan as a pilot program. Fall 2008 Tablet PCs were implemented for all undergraduate students and faculty members teaching undergraduate students except for the College of Architecture due to graphic card demands. Because of the demand for a more powerful graphic card for Architecture student, the university implemented the Mac for these students instead of the Tablet PC.

A Tablet PC committee was organized during this time which included a faculty member from each department across campus. Numerous workshops were offered during these times and instructional materials were developed for faculty members by the committee.

Tablet PC grants were offered to faculty members in 2008 to encourage faculty to enhance teaching methodology in the classroom and student learning. The grants were meant to be an incentive for faculty to adapt current courses or create new courses to enhance the learning environment using the Tablet PC. This could involve interactive teaching and learning uses with their face-toface, hybrid, or online courses. Samples of these grants included the ability to write, sketch, draw, or annotate with the tablet stylus in order to share results instantaneously, or to collaborate in real time which adds new dimensions to classroom interaction.

A Tablet PC survey was deployed to faculty members and students at the beginning of 2008 . Only 34 responded to the survey, out of which $70 \%$ were students. Some expressed benefits included collaboration and classroom integration opportunities, eliminating paper waster, and use for engineering diagrams. Some expressed concerns were small screen size, needs better graphics card, and no build-in CD/DVD. Approximately 50\% who responded to the survey felt that the Tablet PC might aid in writing or sketching equations, employing interactivity, making quick notes with more flexibility, sharing notes electronically, and taking advantage of certain Tablet PC applications specific to their field of study.

Some software that can effectively be utilized in courses includes Windows Journal, WriteOn, PDF Annotator, Classroom Presenter, and OneNote. The only software used for this online class included Windows Journal, WriteOn, and PDF Annotator.

\section{A. Windows Journal}

Is a notetaking application, created by Microsoft. It allows the user to create and organize handwritten notes and drawings. It is very cool when using the Tablet PC.

\section{B. WriteOn}

It was developed by Dr. Joseph Tront, Vinod Eligeti, and Samantha Chandrasekar through a project that was funded through a grant from Microsoft Research. It was developed to allow the user to effectively draw on top of any application shown on the Tablet PC screen. It acts like a virtual transparency. WriteOn has been shown to be a very useful tool for improving both the presentation of information as well as the interactivity in classroom instruction utilizing such software as Maple, MathCad, etc.

\section{PDF Annotator}

It allows you to annotate, edit, highlight, draw and make comments on PDF files. It allows you to save these annotations in the original file. You can restore the original document anytime by removing the annotations.

\section{Classroom Presenter}

It is an interactive system that supports the sharing of digital inking on slides between faculty members and students. Faculty members can gather students' annotations or sketches on slides and choose to display them to everyone in the class. It allows collaboration and active learning in the classroom.

\section{E. OneNote}

It is an electronic version of the three-ring binder which can be used directly for making notes. It allows students to take notes, record a lecture, and synchronize their written annotations with the recording. Students can even search their handwritten notes and replay portions of the lecture.

\section{InSTRUCTIONAL METHODS}

The instructional methodologies include a Blackboard learning environment, theory, required readings/lectures, practice, online forums, activities and assignments, and student/instructor communication. Blackboard learning environment contains weekly modules and the related 
materials, which are theory and practice. The theory component included readings, resource materials, recorded powerpoint lectures, and web links. The practice component included assignments, and discussion forums. Required readings and lectures included reading assigned articles, and listening to recorded powerpoint lectures. Activities and assignments demonstrated achievement of the objectives by completing the activities/assignments according to the criteria. Rubrics were provided for selected assignments. Student/Instructor communication was communicated via Blackboard announcements, email, phone and text messages.

\section{STRATEGIES}

Interactivity and group work are very effective strategies when designing instruction. Interactivity involves interacting with fellow students, with the instructor, and the course content. When creating interactive assignments or activities it is a good idea to involve a mixture of individual and group assignments or activities which involve different interactive levels. Interactivity increases students' interest, improves cognitive processes, and it develops group learning skills (Morgan \& Kinross, 2002).

Group learning lends itself to more student participation and involvement. Students who work in collaborative groups appear more satisfied with their classes and it makes the assignment relevant to the learners (Davis, 1993). It can enhance communication and collaborative skills.

Faculty can transform their teaching styles through some of the features of the Tablet PC. Inking can be a convenient way to create and markup diagrams, graphs, sketches, and mathematical equations. It is convenient way to work out a problem on the fly during class or during office hours, take notes, and mark-up and annotate a website.

It has an impact on grading students' papers. Faculty members can provide written feedback to the students via inking and send their comments back to the students. Sometimes these marked comments in ink can be far easier than typing them.

When designing assignments it is important to make content appropriate, give the students ownership, make it interactive, enhance students' self confidence by providing positive feedback, and making it fun. The following assignments were part of an online graduate course utilizing asynchronous and synchronous modalities. The asynchronous tool utilized was Blackboard and the synchronous tool was Wimba. Tablet PC integration possibilities are explained for each assignment even though graduate students were not required to utilize a Tablet PC.

\section{A. Evaluating eLearning Products}

This was an individual assignment that required students to select an e-learning product using tools such as podcasting, blogging, twitter, surveys, web 2.0 , etc. It required them to describe, evaluate, identify strengths and weaknesses, interactivity, and navigation options of the product.

Students posted their assignments in Blackboard using the assignment manager. Faculty members were able to open their assignment, provide feedback, and grade the assignment. The Tablet PC was utilized to provide written feedback to student's assignments with digital inking on their Word documents. If students submitted PDF documents, PDF Annotator enabled the instructor to annotate on their assignments. Students indicated it felt more personal since handwritten comments were provided to them.

\section{B. Design and Develop an Online Class Unit}

This individual assignment involved having students create a course unit in a course management system such as Blackboard. The course unit was relevant to their discipline.

Faculty members utilized a Tablet PC to discuss class units with each student virtually using Blackboard's, Wimba white board to draw concepts and diagrams of their class unit utilizing inking. Windows Journal was utilized to takes notes concerning the assignment. Faculty members and students were able to collaborate on their possible ideas concerning their online class unit.

Once students designed and developed their online class unit, the faculty member was able to provide feedback on their Word, PDF or Powerpoint files by inking with their Tablet PC.

\section{Evaluating Online Course}

This was a group interactive assignment that required students to explore online courses available on the web such as MIT, ITunes University, etc. The students had to evaluate whether the course encourage contact between students and faculty, emphasized time on task, communicated high expectations to the students, and respected diverse talents and ways of learning. Their evaluation was based on a rubric which expected overall visual appeal, and relevant content.

This assignment allowed students to compare different online courses available on the Internet. Students had to create a powerpoint to summarize their findings. They had to upload their powerpoint and present their findings via Wimba. Their presentation was archived just incase some students could not attend their session. By sharing their findings with other students virtually via Wimba, they were able to explain and justify their findings on these courses to the entire class virtually.

Faculty member utilizing a Tablet PC could write on the Powerpoint presentation by emphasizing certain portions of the presentation. Additionally, WriteOn was utilized to annotate on the website.

\section{Synchronous Group Instructional Research}

This was a group assignment that involved researching an assigned topic, creating a Powerpoint presentation, and presenting it in a synchronous tool such as Wimba. Some topics included learning analysis and motivation, cognitive learning strategies, constructivism approaches to elearning, Tablet PC effective approaches, and future trends in distance or face-to-face learning.

Break out rooms were created for each group in Wimba with instructor privileges for the groups to collaborate on their assignment. Students were able to upload their final presentations just like a faculty member. Each group had to present their topic to the rest of the class either synchronously or asynchronously depending on their course delivery. Asynchronous delivery students invited the rest of the class to their presentation but it was not mandatory for the rest of the class to attend at the time it was presented. Each group archived their presentation so class 
members could view the session at their convenience asynchronously.

When a group presented their Powerpoint synchronously, they had to click through their presentation, answer questions, and read chat all at the same time if other students and the faculty member attend the session. This taught them that it can be difficult to multitask through different venues and still keep students engaged in their learning. The groups needed to interact with each other and change their role from student to faculty member. This process emphasized student-to-student interaction through group tasks and cooperative activities which increased as they moved from teaching to a learning paradigm (Bower, 2001).

Again, as indicated in the other assignments, the faculty members were able to ink on the students' Powerpoint presentations and provide constructive feedback.

\section{E. Discussion Boards}

The lack of face-to-face interaction can be substituted by online discussion (Yang \& Cornelious, 2005). As a result, this online course was designed to have at least one interactive discussion forum each week. The discussion forums were based on numerous research papers. Some weeks involved a group of students being responsible for facilitating the forum.

These forums made the students interact each week with everyone in the class including the faculty member. The faculty member could utilize WriteOn to add inking to the response. The majority of weekly discussions were based on outside papers they had to read. Students are expected to answer the specific questions posted, raise questions and add comments to postings by others. They were given points for their weekly discussion forums based on a rubric.

In traditional classroom settings faculty members can use their understanding of their students through observation of body language, verbal response, and eye contact to create an effective learning experience (Bower, 2001). The instructor needs to reply to more on nonverbal communication cues and employ active listening skills. Faculty members can pose additional questions for clarification and summarize what is said to ensure accurate information exchange (Rybarczyk, 2007). As with the previous assignment, this can be done utilizing inking with the Tablet PC.

\section{CONCLUSION}

The Tablet PC can change the way students and faculty members interact. It can support active learning and it can add value to interaction in different learning modalities such as face-to-face, hybrid, and online courses. Tablet PCs can encourage creative considerations to improve teaching and learning. The ability of the Tablet PC to allow writing directly on the screen opens up many new possibilities to the pedagogy of teaching problem-solving.

Faculty members need to rethink how they can effectively teach using a Tablet PC. This paper illustrates some strategies but what are the next steps. How can the Tablet PC be utilized further in online courses? What is the impact on face-to-face courses? Just like any technology, adoption rate among faculty takes time. It involves change. As the Tablet PCs are being utilized in future courses, it is important for faculty members to believe that Tablet PCs are effective for student learning. It has the potential for enhancing online course delivery.

\section{REFERENCES}

[1] B. L. Bower, "Distance Education: Facing the Faculty Challenge," Online Journal of Distance Learning Administration, vol. 4, no. 5, 2001.

[2] Butler, K. (2003). How to Keep Online Students Motivated. Australian Flexible Learning Community

[3] S. Carlson, "The Next-Generation Classroom," The Chronicle of Higher Education, vol. 50, no. 25, 2004, pp. A26.

[4] B. G. Davis, Tools for Teaching, Jossey-Bass Publishers, San Francisco, 1993.

[5] J. Harvey and N. Mogey, "Implementing Learning Technology," Learning Technology Dissemination Initiative, 1997.

[6] H. Hutchins, "Instructional Immediacy and the Seven principles: Strategies for Facilitating Online Courses," Online Journal of Distance Learning Administration, vol. 6, no. 32003.

[7] M. J. Lage and G. J. Platt and M. Treglia, "Inverting the Classroom: A Gateway to Creating an Inclusive Learning Environment," Journal of Economic Education, vol 31, no1, 2000, pp. 3043. (doi:10.2307/1183338)

[8] C. K. Morgan and C. Kinross, "Facilitating Online Interactivity Among Remotely Located Land Management Students," Electronic Journal of Instructional Science and Technology, 2002.

[9] D. G. Oblinger and B. L. Hawkins, "The Myth about Online Course Development," Educause Review, vol. 41, no. 1, 2006, pp. 14-15.

[10] B. J. Rybarczyk, "Tools of Engagement: Using Case Studies in Synchronous Distnace-Learning Environments," The Journal of College Science Teaching, vol. 37, no. 1, 2007, pp. 31-3.

[11] J. Tront and V. Eligeti and J. Prey, "Classroom Presentations Using Tablet PCs and WriteOn," Frontiers in Education Conference, $36^{\text {th }}$ Annual, 2006, pp. 1-5.

[12] S. Waterhouse, The Power of eLearning, Pearson Education, Inc. 2005.

[13] Y. Yang and L. F. Cornelious, "Preparing Instructors for Quality Online Instruction," Online Journal of Distance Learning Administration, vol. 8, no. 1, 2005.

\section{AUTHORS}

Pamela Lowry is with Lawrence Technological University, Southfield, MI 48075 USA (e-mail: plowry@ltu.edu).

This article was modified from a presentation at the ICELW 2009 conference in New York, NY, USA, June 2009. Submitted 3 July 2009. Published as resubmitted by the authors on 10 October 2009. 